\title{
Preparation of Glass Plate-Supported Nanostructure ZnO Thin Film Deposited by Sol-Gel Spin-Coating Technique and Its Photocatalytic Degradation to Monoazo Textile Dye
}

\author{
Mohammad Hossein Habibi and Mohammad Khaledi Sardashti \\ Catalysis Division, Department of Chemistry, University of Isfahan, Isfahan 81746-73441, Iran \\ Correspondence should be addressed to Mohammad Hossein Habibi, mhhabibi@yahoo.com
}

Received 9 July 2007; Accepted 8 January 2008

Recommended by Robert Dorey

\begin{abstract}
Glass plate-supported nanostructure $\mathrm{ZnO}$ thin films were deposited by sol-gel spin coating. Films were preheated at $275^{\circ} \mathrm{C}$ for 10 minutes and annealed at 350,450 , and $550^{\circ} \mathrm{C}$ for 80 minutes. The $\mathrm{ZnO}$ thin films were transparent ca $80-90 \%$ in visible range and revealed that absorption edges at about $370 \mathrm{~nm}$. The $c$-axis orientation improves and the grain size increases which was indicated by an increase in intensity of the (002) peak at $34.4^{\circ}$ in XRD corresponding to the hexagonal ZnO crystal. The photocatalytic degradation of X6G an anionic monoazo dye, in aqueous solutions, was investigated and the effects of some operational parameters such as the number of layer and reusability of $\mathrm{ZnO}$ nanostructure thin film were examined. The results showed that the five-layer coated glass surfaces have a very high photocatalytic performance.
\end{abstract}

Copyright (c) 2008 M. H. Habibi and M. K. Sardashti. This is an open access article distributed under the Creative Commons Attribution License, which permits unrestricted use, distribution, and reproduction in any medium, provided the original work is properly cited.

\section{INTRODUCTION}

Textile industry wastewater is heavily charged with unconsumed dyes, surfactants, and sometimes traces of metals. These effluents cause a lot of damage to the environment. Many methods, including biosorption [1], conventional activated sludge treatment process [2], electrochemical technologies [3, 4], and reverse osmosis, [5] have been applied on wastewater treatment. However, new environmental laws may consider the spent adsorbents or sludge as hazardous wastes that require further treatment. Consequently, intensive researches on novel technologies with more efficiency and less energy consumption have been stimulated. Photocatalysis using a semiconductor as a photocatalyst is an alternative to conventional methods [6-11]. As a well-known photocatalyst, $\mathrm{ZnO}$ has been paid much attention in the degradation and complete mineralization of environmental pollutants. Since $\mathrm{ZnO}$ has approximately the same band gap energy $(3.2 \mathrm{eV})$ as $\mathrm{TiO}_{2}$, its photocatalytic capacity is anticipated to be similar to that of $\mathrm{TiO}_{2}$. However, the greatest advantage of $\mathrm{ZnO}$ is that it absorbs large fraction of the solar spectrum and more light quanta than $\mathrm{TiO}_{2}$ [12]. Some researches have highlighted the performance of $\mathrm{ZnO}$ on degrading some organic compounds [13]. On the other hand, the use of conventional powder catalyst results in disadvantages in stirring during the reaction and in the separation of powder after the reaction. Preparation of film catalysts will make it possible to overcome these disadvantages and to extend the industrial applications [14]. The sol-gel process, as a simple and easy dip-coating means, is one of the versatile methods to prepare thin film-supported nanosized particles without complicated instruments such as CVD. Thin film photocatalysts, with their high photocatalytic ability, high stability, and convenient reuse, have received more and more attention. However, there has been little success in finding thin film photocatalyst that can operate effectively with visible light as yet. In this context, we have paid much attention in preparing thin films of $\mathrm{ZnO}$ on glass plates by a sol-gel process and studying its photocatalytic ability for the degradation of X6G an anionic monoazo textile dye. In this paper, a commercial glass-plate was successfully used as substrate to prepare highest $c$-axis oriented $\mathrm{ZnO}$ nanostructure thin film by sol-gel dip-coating process. The $\mathrm{ZnO} /$ glass films have been employed in photocatalytic degradation of textile dye. 


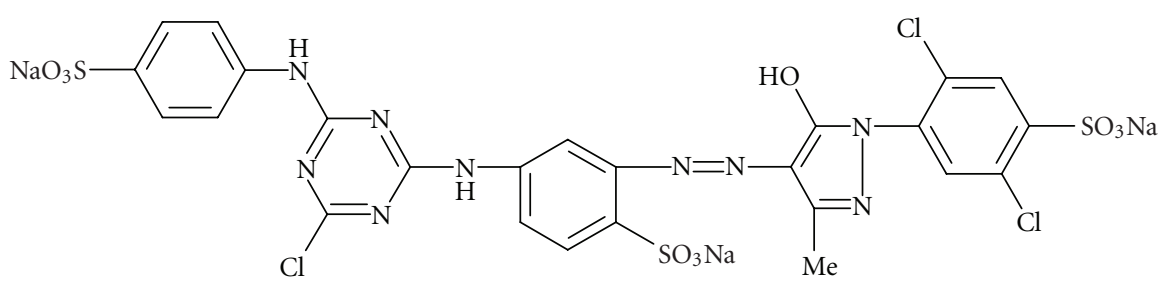

FIGURE 1: Chemical structure of commercial diazo dye of light yellow (X6G).

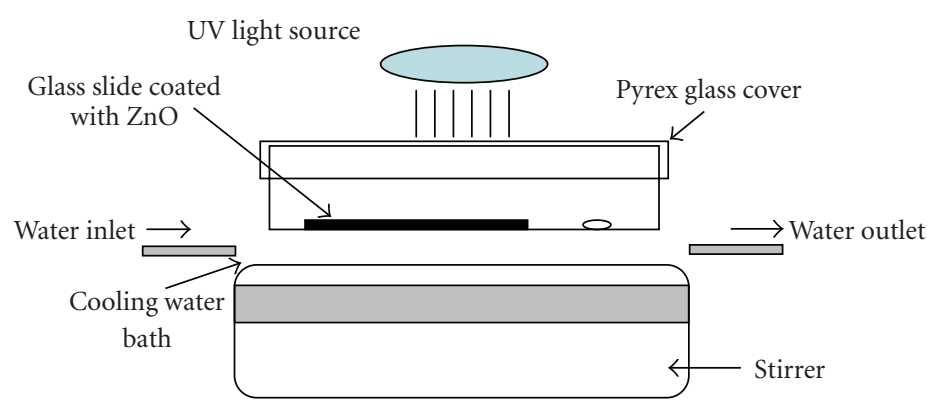

FIGURE 2: Schematic diagram of photoreactor for degradation.

The result shows that the $\mathrm{ZnO} /$ glass film is a photocatalyst with higher activity. It is very interesting and significant to research promising photocatalysts.

\section{EXPERIMENTAL}

\subsection{Preparation of sol}

All the chemicals were analytic grade reagents without further purification, and purchased from Merck Company. Light YellowX6G dye (C. I. Reactive Yellow 2, Rmm872.5) was obtained from Youhao (China) and has chemical structure shown in Figure 1. Nanocrystalline $\mathrm{ZnO}$ films were prepared on microscope glass slide $(75 \mathrm{~mm} \times 25 \mathrm{~mm} \times 1 \mathrm{~mm})$ substrate (washed with ethanol and dilute acid) by a sol-gel method. Sol solution was prepared by adding $3.10 \mathrm{~g}$ Zinc acetate dihydrate $\left(\mathrm{Zn}\left(\mathrm{CH}_{3} \mathrm{COO}\right)_{2} \cdot 2 \mathrm{H}_{2} \mathrm{O}: \mathrm{ZnAc} \cdot 2 \mathrm{H}_{2} \mathrm{O}\right), 0.86 \mathrm{~g}$ monoethanolamine (MEA), and adequate deionized water to $15 \mathrm{~mL}$ isopropanol alcohol, then heated to $60^{\circ} \mathrm{C}$ with continuous stirring for 60 minutes. The coating substrate (microscope glass slid) was preheated at $275^{\circ} \mathrm{C}$ for 10 minutes in air after each coating. The sol-gel coating was made usually a day after the sol solution was prepared and the molar ratio of MEA to Zinc acetate was maintained at $1: 1$.

\subsection{Film deposition}

The films of $\mathrm{ZnO}$ were prepared by spin coating method onto substrate with $3000 \mathrm{rpm}$ for 45 seconds(the spinner reached $3000 \mathrm{rpm}$ after $5 \mathrm{~s}$ which was maintained for $40 \mathrm{~s}$ ). Films were annealed at furnace at $550^{\circ} \mathrm{C}$ for 80 minutes. Precursor solution did not produce any precipitation after 30 days. This spinning-drying procedure was repeated from 2 to 10 times. The microscope glass slide $(75 \mathrm{~mm} \times 25 \mathrm{~mm} \times 1 \mathrm{~mm}$ : cleaned in dilute $\mathrm{HCl}$ solution and ethanol) was used as sub- strate. Film deposition was carried out in air at room temperature by a rate $3000 \mathrm{rpm}$ for $30 \mathrm{~s}$. After each coating, the films were preheated at $275^{\circ} \mathrm{C}$ for 10 minutes, and postheated at $550^{\circ} \mathrm{C}$ for 80 minutes. The deposition was repeated for $2,4,5,6,8$, and 10 times to obtain a film with different thickness.

\subsection{Characterization of thin films}

The structure and crystalline size were determined by XRD diffraction (Bruker D8 advanced X-ray diffractometer: $\mathrm{Cu} \mathrm{K}_{\alpha}$ radiation, Scan rate $0.032 \theta \mathrm{s}^{-1}$ ). X-ray diffraction shows zincite structure with $c$-axis orientation (002). Optical transmittance was measured by spectrophotometer (Varian Cary 500 Scan).

\subsection{Photocatalytic degradation}

The photocatalytic degradation experiments were carried out in a simple $(40 \mathrm{~cm} \times 15 \mathrm{~cm} \times 15 \mathrm{~cm})$ oxidation reactor (see Figure 2), placed in a $25^{\circ} \mathrm{C}$ water bath. Slide with 5 layers that placed in $25 \mathrm{~mL} 10 \mathrm{ppm}$ X6G solution was irradiated with two $8 \mathrm{~W}$ lamps (Philips; $\lambda=365 \mathrm{~nm}$ ) placed $5 \mathrm{~cm}$ above the solutions. Concentration is measured by spectrophotometer (Varian Cary 500 Scan). In all experiments, $25 \mathrm{~mL}$ of $10 \mathrm{ppm}$ X6G solution was used with stirring during the irradiation.

\section{RESULTS AND DISCUSSION}

\subsection{Stability of sol}

Sol was prepared by altering the ratio of $\mathrm{Zn}(\mathrm{Ac})_{2} \cdot 2 \mathrm{H}_{2} \mathrm{O}$ : MEA.In this work, the best sol was obtained with a $\mathrm{Zn}(\mathrm{Ac})_{2}$. $2 \mathrm{H}_{2} \mathrm{O}$ : MEA molar ratio $1: 1$ in isopropanol. Increasing the 


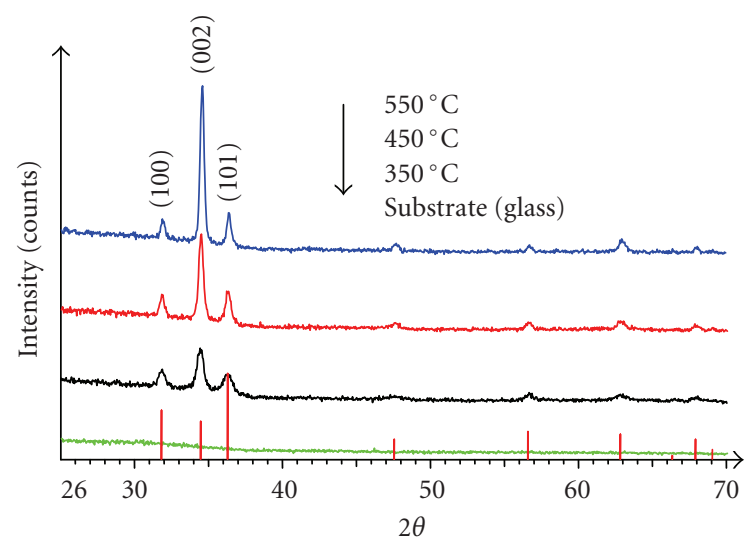

FIgURE 3: XRD pattern of the $\mathrm{ZnO}$ thin films on microscope glass slide by five spin-coatings ( 5 layers), preheated at $275^{\circ} \mathrm{C}$ for $10 \mathrm{~min}$ utes and postheated for 80 minutes at different temperature.

water content and decreasing the time of reflux may change the sol to gel immediately. MEA was added to keep the sol solutions stable and clear for a long period (more than 30 days). There are many factors affecting the crystallization behavior of the films such as substrate, the time and temperature of reflux, molar ratio of starting material, and composition of stabilizers such as MEA. In this work, sol was prepared at $60^{\circ} \mathrm{C}$ for 60 minutes until a clear homogeneous solution appeared. The XRD pattern of the $\mathrm{ZnO}$ thin films on microscope glass slide by five spin-coating (5-layer) preheated at $275^{\circ} \mathrm{C}$ for 10 minutes and postheated for 80 minutes at different temperature, $350^{\circ} \mathrm{C}, 450^{\circ} \mathrm{C}$, and $550^{\circ} \mathrm{C}$, was shown in Figure 3. There are three distinct differences between the XRD of thin films and $\mathrm{ZnO}$ powder. Firstly, diffraction peaks of thin films have lower intensity and higher FWHM (Fully Width at Half Maximum) compared to powder; secondly, the films are predominantly (002) oriented, and finally films are crystallized (wurtzite) at comparatively higher temperature as compared to powder that has been prepared from chemical producers. Increase of annealing temperature affected the intensity of (002) peak which was the highest at $550^{\circ} \mathrm{C}$. The $\mathrm{ZnO}$ films grow with a (002) orientation is kinetically preferred, which in turn likely reflects the fact that the highest density of $\mathrm{Zn}$ atoms is found along the (002) plane [15].

Figure 4 shows the XRD pattern of the $\mathrm{ZnO}$ thin film on microscope glass for various layers by spin-coating $(2,4$, 6,8 , and 10 layers), preheated at $275^{\circ} \mathrm{C}$ for 10 minutes and postheated for 80 minutes at $550^{\circ} \mathrm{C}$.

Figures 5(a)-5(c) show the scanning electron microscopy (SEM) image of the nanostructure $\mathrm{ZnO}$ thin films at various temperatures, and Figure 5(d) shows atomic force microscopy (AFM) image of $\mathrm{ZnO}$ thin film at $450^{\circ} \mathrm{C}$ that prepared by spin coating method on a glass substrate. The average grain size of nanostructure $\mathrm{ZnO}$ thin films was near $40 \mathrm{~nm}$, and the crystal size increased with increasing the annealing temperature. As shown in Figures 5(a)-5(d), thin films of $\mathrm{ZnO}$ prepared by spin coating reveal the formation of a porous granular surface.

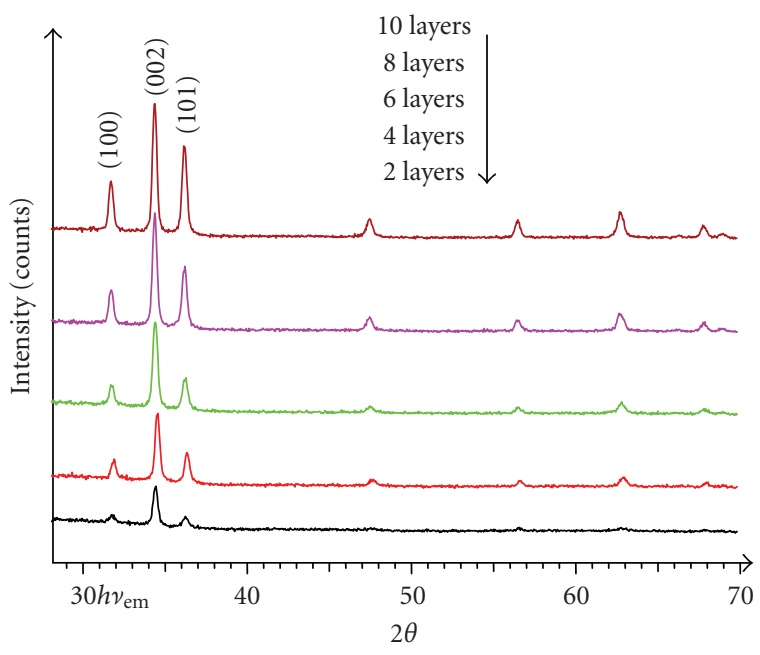

FIGURE 4: XRD pattern of the $\mathrm{ZnO}$ thin films on microscope glass with different layers $(2,4,6,8$, and 10 layers $)$, preheated at $275^{\circ} \mathrm{C}$ for 10 minutes and postheated for 80 minutes at $550^{\circ} \mathrm{C}$.

TABle 1: The grain size (crystalline size) of $\mathrm{ZnO}$ thin films with various times of coating, postheated at $550^{\circ} \mathrm{C}$.

\begin{tabular}{lccc}
\hline Samples of thin film & $2 \theta$ & FWHM $=\beta$ & $D(\mathrm{~nm})$ \\
\hline 2-layer & 34.484 & 0.350 & 23.9 \\
4-layer & 34.471 & 0.342 & 24.7 \\
6-layer & 34.743 & 0.358 & 23.5 \\
8-layer & 34.443 & 0.335 & 25.1 \\
10-layer & 34.462 & 0.332 & 25.1 \\
\hline
\end{tabular}

Optical transmittance of $\mathrm{ZnO}$ thin films with 5 times spin coating, preheated at $275^{\circ} \mathrm{C}$ for 10 minutes and postheated at various temperatures, $350^{\circ} \mathrm{C}, 450^{\circ} \mathrm{C}$, and $550^{\circ} \mathrm{C}$, is shown in Figure 6. The absorption at about $370 \mathrm{~nm}$ corresponds to an electronic transition beyond the bandgap, $3.2 \mathrm{eV}$ of the wurtzite crystalline phase of $\mathrm{ZnO}$.

The crystalline size of $\mathrm{ZnO}$ in the films was calculated by Scherrer's formula $D=0.9 \lambda / \beta \operatorname{Cos} \theta$, where $D$ is the grain size, $\lambda(1.548 \AA)$ is the wavelength of $\mathrm{X}$-ray radiation used, $\beta$ is the full width at half maximum (FWHM) of the diffraction peak, and $\theta$ is the Bragg diffraction angle of the XRD peak. The average crystalline size of $\mathrm{ZnO}$ in the films annealed at $350^{\circ} \mathrm{C}$, $450^{\circ} \mathrm{C}$, and $550^{\circ} \mathrm{C}$ was about 16,23 and $25 \mathrm{~nm}$, respectively. The average crystalline size of $\mathrm{ZnO}$ in the films with various times of coating annealed at $550^{\circ} \mathrm{C}$ is shown in Table 1 . It was observed that the $c$-axis orientation improves, and the grain size increases as indicated by an increase in intensity of the (002) peak and the decrease in the FWHM (Fully Width at Half Maximum) high with the increase of annealed temperature. An average grain size was about $25 \mathrm{~nm}$.

\subsection{Photocatalytic activity}

Evaluation of the films as potential photocatalyst for water pollutant purification was based on the degradation of a 


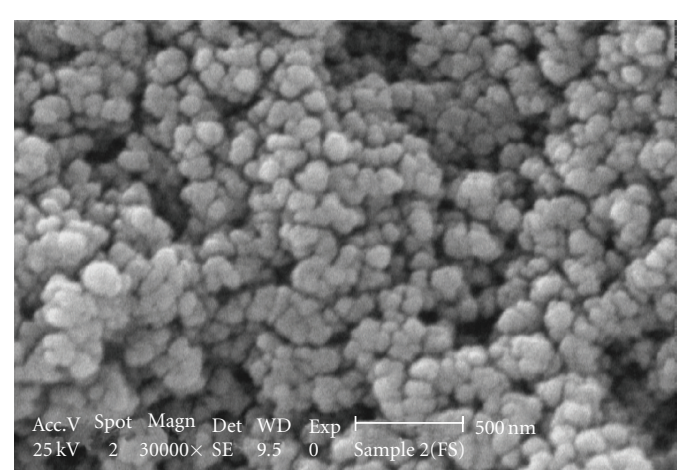

(a)

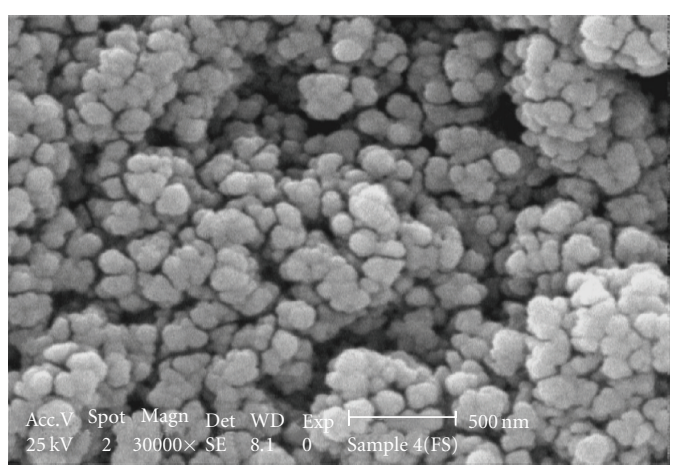

(c)

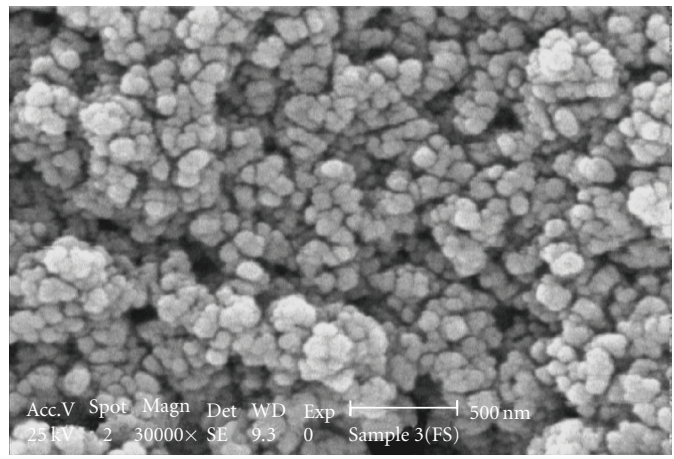

(b)

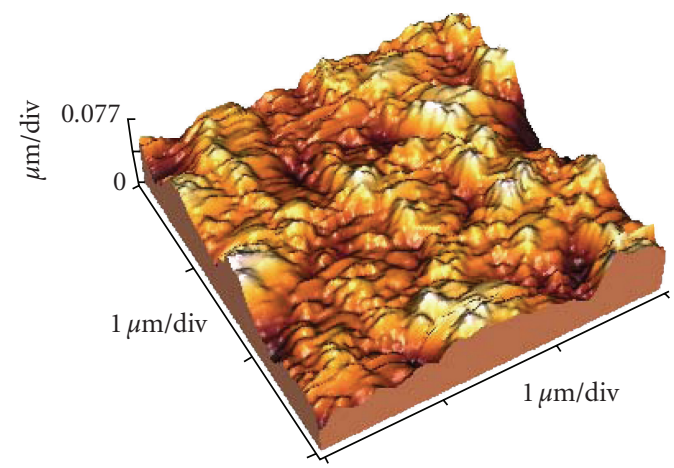

(d)

Figure 5: ((a)-(c)) SEM images of the $\mathrm{ZnO}$ thin film at different temperature $\left((\mathrm{a})=350^{\circ} \mathrm{C},(\mathrm{b})=450^{\circ} \mathrm{C}\right.$, and $\left.(\mathrm{c})=550^{\circ} \mathrm{C}\right),(\mathrm{d}) \mathrm{AFM}$ image $\mathrm{ZnO}$ thin film prepared at $450^{\circ} \mathrm{C}$.

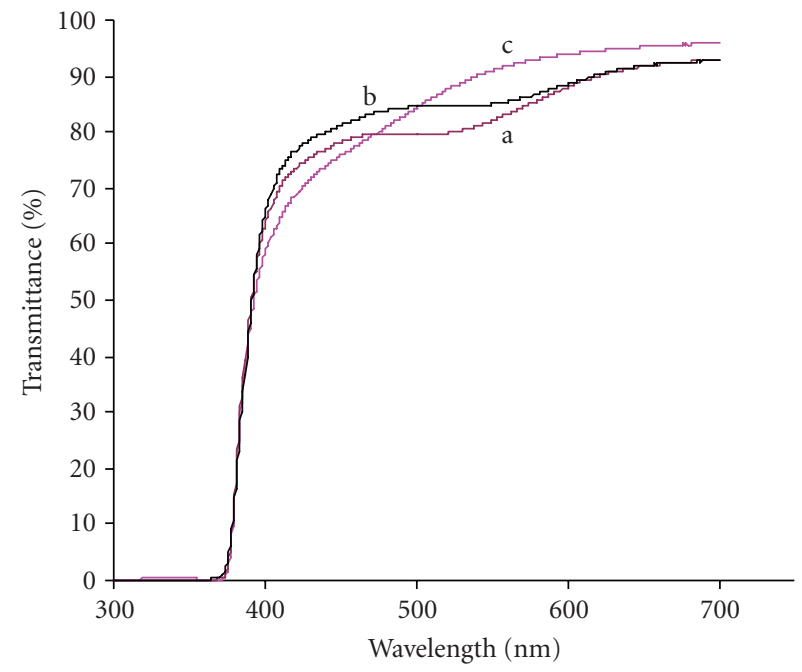

Figure 6: Optical transmittance of $\mathrm{ZnO}$ thin films, postheated at various temperatures $\left(\mathrm{a}=350^{\circ} \mathrm{C}, \mathrm{b}=450^{\circ} \mathrm{C}\right.$, and $\left.\mathrm{c}=550^{\circ} \mathrm{C}\right)$.

model azo dye, X6G. The results showed that nanostructure $\mathrm{ZnO}$ thin film and UV light $(365 \mathrm{~nm})$ had a negligible effect when they were used on their own after 240 minutes. Figure 7

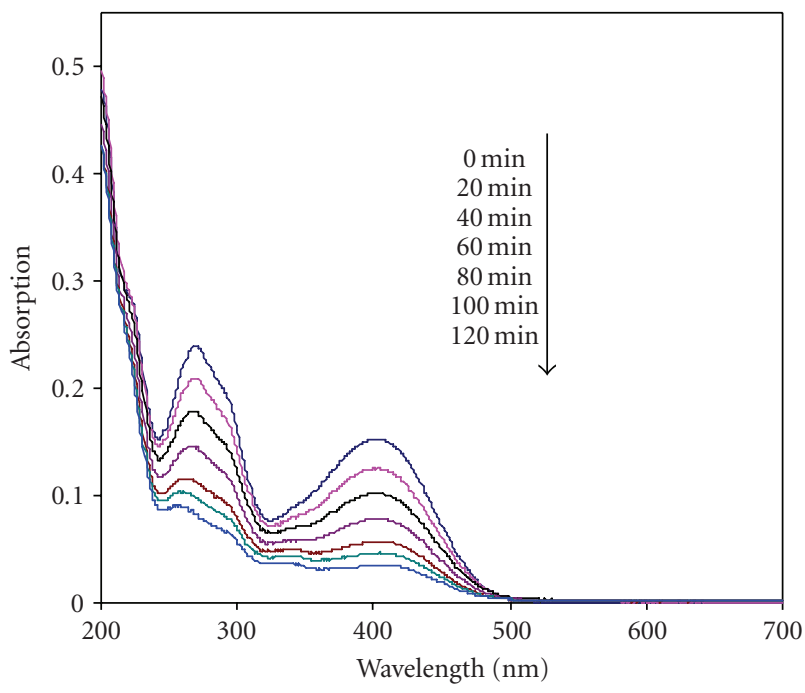

Figure 7: UV-visible spectra of X6G (initial concentration of $\mathrm{X} 6 \mathrm{G}=0.013 \mathrm{mM}$ ) in deionized water after photocatalytic degradation under UV irradiation on $\mathrm{ZnO}$ film with 5 layers.

shows the degradation of 10 ppm X6G under UV irradiation (365 nm) using $\mathrm{ZnO}$ thin film. Glass plate supported $\mathrm{ZnO}$ thin films with different layers $(2,4,5,6,8$, and 10 layers) 


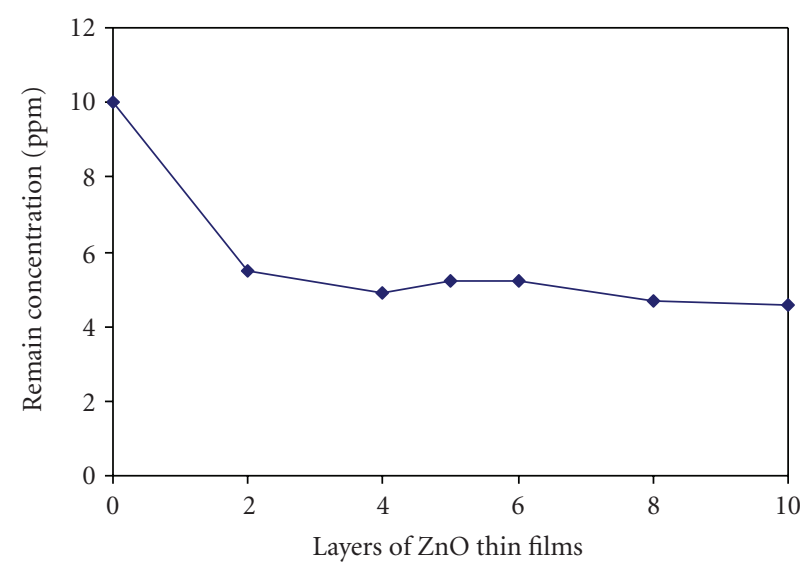

FIgURe 8: X6G concentration (ppm) (initial concentration of $\mathrm{X} 6 \mathrm{G}=0.013 \mathrm{mM}$ ) after photocatalytic degradation under UV irradiation for 80 minutes on $\mathrm{ZnO}$ films with various layers.

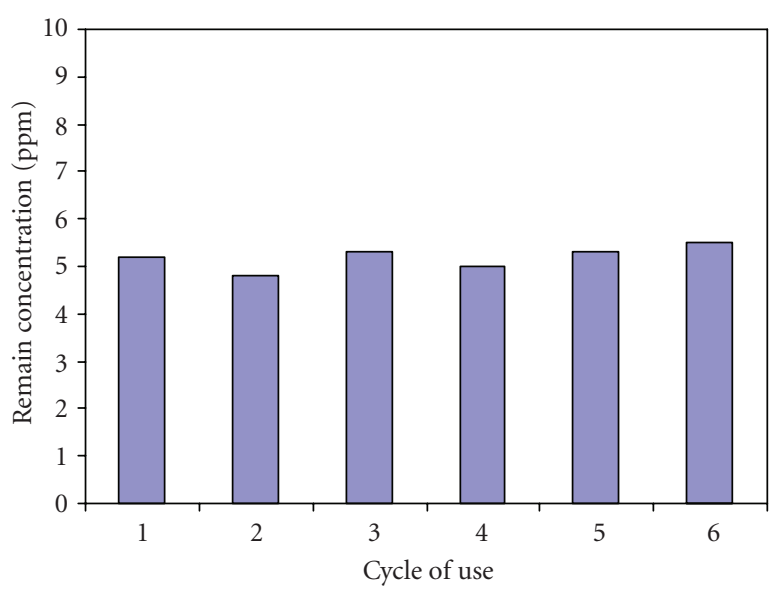

Figure 9: X6G concentration (ppm) (initial concentration of $\mathrm{X} 6 \mathrm{G}=0.013 \mathrm{mM}$ ) after photocatalytic degradation under UV irradiation for 80 minutes on $\mathrm{ZnO}$ film with 5-layer six-cycle reuse.

were tested for degradation of the X6G dye for 80 minutes (see Figure 8).

Thin films with 5 layers were reused five times and did not show much catalytic activity change (see Figure 9).

\section{CONCLUSION}

Zinc acetate and MEA have proved to be suitable compounds to obtain high quality pure coatings. These precursor compounds and the proper annealing conditions have proved to be suitable to produce stable guest oxide nanocrystalline size. The thin films show good photocatalytic activity for degradation of X6G dye solution.

\section{ACKNOWLEDGMENT}

The authors wish to thank the Center of Excellency (Chemistry) University of Isfahan for partial financial support to this work.

\section{REFERENCES}

[1] Z. Aksu, "Application of biosorption for the removal of organic pollutants: a review," Process Biochemistry, vol. 40, no. 34, pp. 997-1026, 2005.

[2] A. Katsoyiannis and C. Samara, "Persistent organic pollutants (POPs) in the conventional activated sludge treatment process: fate and mass balance," Environmental Research, vol. 97, no. 3, pp. 245-257, 2005.

[3] G. Chen, "Electrochemical technologies in wastewater treatment," Separation and Purification Technology, vol. 38, no. 1, pp. 11-41, 2004.

[4] D. Rajkumar and K. Palanivelu, "Electrochemical treatment of industrial wastewater," Journal of Hazardous Materials, vol. 113, no. 1-3, pp. 123-129, 2004.

[5] A. Bódalo-Santoyo, J. L. Gómez-Carrasco, E. Gómez-Gómez, F. Máximo-Martín, and A. M. Hidalgo-Montesinos, "Application of reverse osmosis to reduce pollutants present in industrial wastewater," Desalination, vol. 155, no. 2, pp. 101-108, 2003.

[6] A. Fujishima, T. N. Rao, and D. A. Tryk, "Titanium dioxide photocatalysis," Journal of Photochemistry and Photobiology C, vol. 1, no. 1, pp. 1-21, 2000.

[7] A Fujishima and K. Honda, "Electrochemical photolysis of water at a semiconductor electrode," Nature, vol. 238, pp. 37-38, 1972.

[8] D. Chatterjee and S. Dasgupta, "Visible light induced photocatalytic degradation of organic pollutants," Journal of Photochemistry and Photobiology C, vol. 6, no. 2-3, pp. 186-205, 2005.

[9] M. H. Habibi, A. Hassanzadeh, and S. Mahdavi, "The effect of operational parameters on the photocatalytic degradation of three textile azo dyes in aqueous $\mathrm{TiO}_{2}$ suspensions," Journal of Photochemistry and Photobiology A, vol. 172, no. 1, pp. 89-96, 2005.

[10] M. H. Habibi, A. Hassanzadeh, and A. Zeini-Isfahani, "Effect of dye aggregation and azo-hydrazone tautomerism on the photocatalytic degradation of Solophenyl red 3BL azo dye using aqueous $\mathrm{TiO}_{2}$ suspension," Dyes and Pigments, vol. 69, no. 3, pp. 111-117, 2006.

[11] M. H. Habibi and H. Vosoghian, "Photocatalytic degradation of some organic sulfides as environmental pollutants using titanium dioxide suspension," Journal of Photochemistry and Photobiology A, vol. 174, no. 1, pp. 45-52, 2005.

[12] S. Sakthivel, B. Neppolian, M. V. Shankar, B. Arabindoo, M. Palanichamy, and V. Murugesan, "Solar photocatalytic degradation of azo dye: comparison of photocatalytic efficiency of $\mathrm{ZnO}$ and $\mathrm{TiO}_{2}$," Solar Energy Materials and Solar Cells, vol. 77, no. 1, pp. 65-82, 2003.

[13] C. Lizama, J. Freer, J. Baeza, and H. D. Mansilla, “Optimized photodegradation of reactive blue 19 on $\mathrm{TiO}_{2}$ and $\mathrm{ZnO}$ suspensions," Catalysis Today, vol. 76, no. 2-4, pp. 235-246, 2002.

[14] K. Iketani, R.-D. Sun, M. Toki, K. Hirota, and O. Yamaguchi, "Solgel-derived $\mathrm{V}_{X} \mathrm{Ti}_{1-X} \mathrm{O}_{2}$ films and their photocatalytic activities under visible light irradiation," Materials Science and Engineering B, vol. 108, no. 3, pp. 187-193, 2004.

[15] S. Amirhaghi, V. Cracium, D. Cracium, J. Elders, and I. W. Boyd, "Low temperature growth of highly transparent c-axis oriented $\mathrm{ZnO}$ thin films by pulsed laser deposition," Microelectronic Engineeering, vol. 25, no. 2-4, pp. 321-326, 1994. 

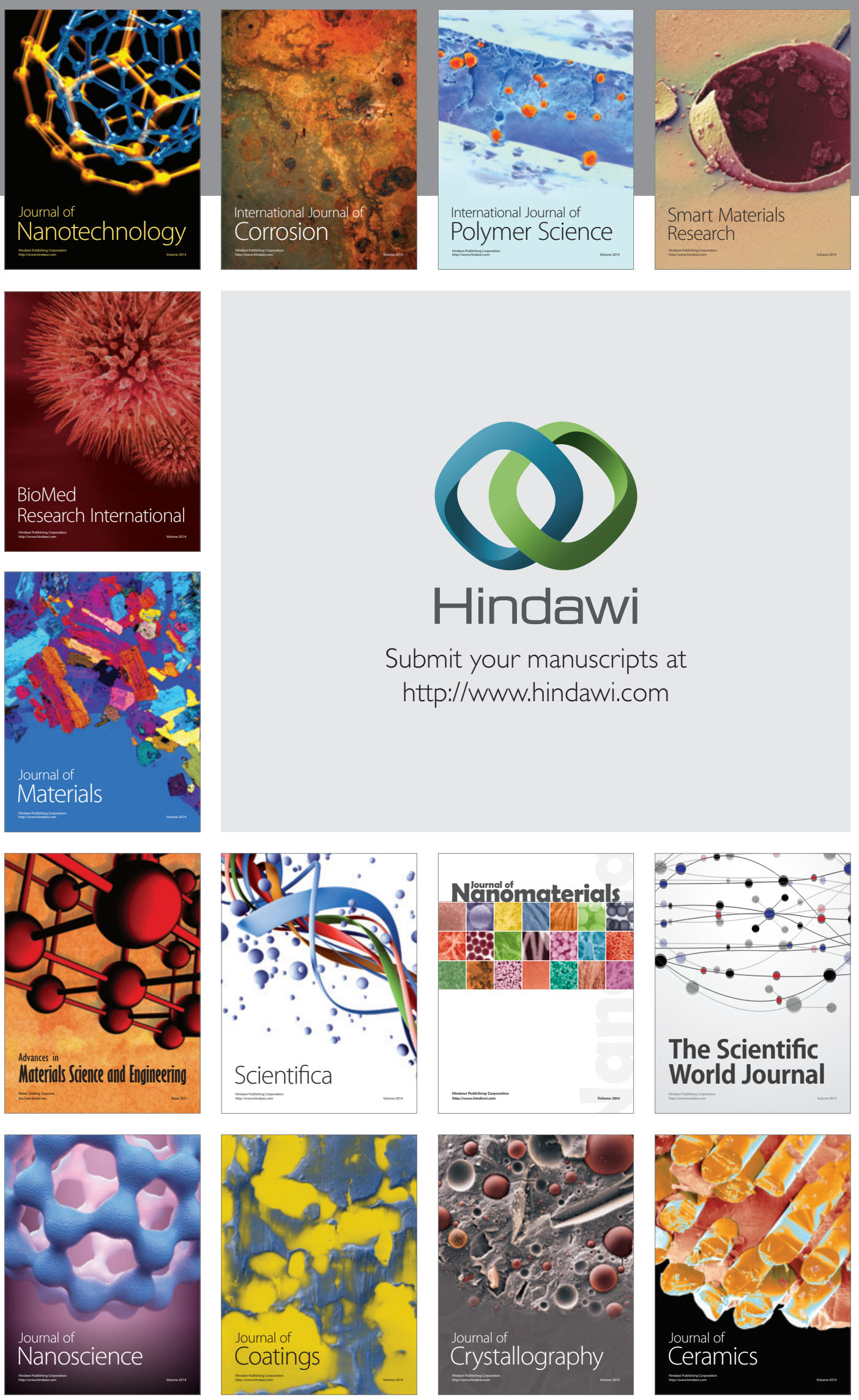

The Scientific World Journal

Submit your manuscripts at

http://www.hindawi.com

\section{World Journal}

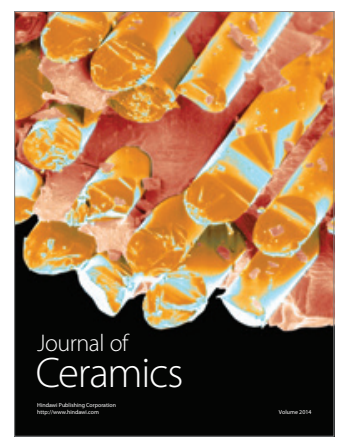

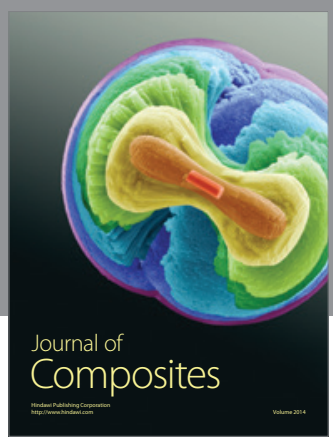
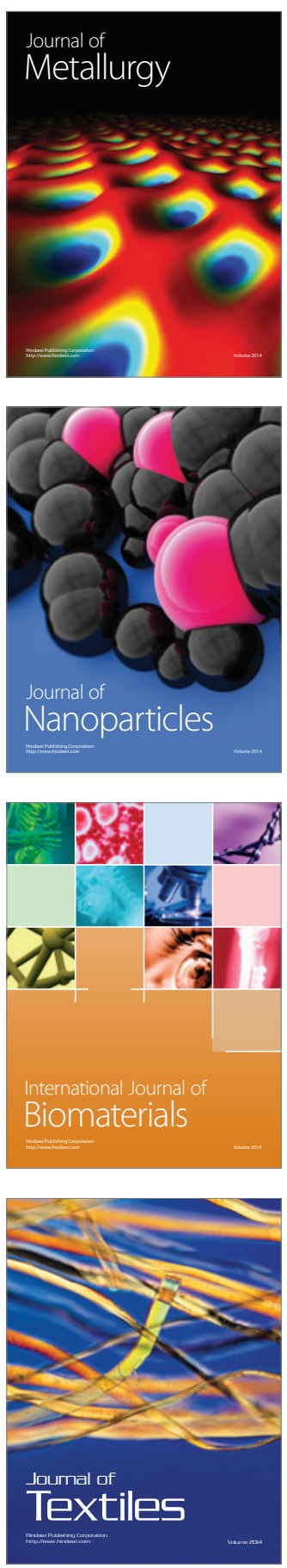